\title{
A Qualitative Study of HIV Treatment Adherence Support from Friends and Family among Same Sex Male Couples
}

\author{
— Support for HIV Medication Adherence from Friends and Family \\ Scott Stumbo, Judith Wrubel, Mallory O. Johnson \\ University of California, San Francisco, USA. \\ Email: Mallory.johnson@ucsf.edu \\ Received February 16 $6^{\text {th }}, 2011$; revised March 21 ${ }^{\text {st }}$, 2011; accepted April 27 $7^{\text {th }}, 2011$.
}

\begin{abstract}
HIV-positive individuals seek support for medication adherence from a variety of sources—spouses, family and friends. We conducted a qualitative study of twenty same sex male couples where we asked men to give narratives of support received for medication adherence from their partner, family and friends. Men in couple relationships did not routinely seek tangible or practical assistance for adherence from friends and family but almost exclusively from partners. These men did seek and receive informational and emotional support from friends and family. These results have implications for designing interventions for medication support when an individual is in a relationship.
\end{abstract}

Keywords: Social Support, Gay Couples, Antiretroviral Adherence, HIV/AIDS

Social support through social networks provide logistical and emotional support that is seen as beneficial across many disease contexts (Berkman \& Syme, 1979; Kulik \& Mahler, 1989; Lewis \& Rook, 1999). The same has held true in studies of coping with HIV and HIV medication adherence (Ammassari et al., 2002; Catz, Kelly, Bogart, Benotsch, \& McAuliffe, 2000; Murphy, Marelich, Hoffman, \& Steers, 2004; Power et al., 2003). Less, however, is known about how gay men in couples support one another around HIV medication adherence and less still is known about how gay men in couples seek or receive support from family and friends in their social network. In this paper we specifically explore the offering and receipt of support from friends and family when an individual on HIV medications also has a primary partner.

Two major aspects of social support we explore are the type of support (of what does the support consist) and the source (who is providing the support). The types of support are generally categorized as 1) tangible/practical/aid, 2) emotional/affective, and 3) informational (Dakof \& Taylor, 1990). Sources of support include 1) partners/spouses, 2) parents, 3) other family, 4) friends, and 5) health care workers (Nott, Vedhara, \& Power, 1995). The type of support may be classified as either perceived available support or actual received support.

Some previous studies have focused on the intersection of type and source of support (DiMatteo, 2004; Hamilton, Razzano, \& Martin, 2007; Primomo, Yates, \& Woods, 1990). However, quite often researchers combine the sources of support into an overall measure of generalized (often perceived) support. This approach does not allow for analysis based on the specific source of support (Newell, Baral, Pande, Bam, \& Malla, 2006; Revenson, Schiaffino, Majerovitz, \& Gibofsky, 1991; Walley, Khan, Newell, \& Khan, 2001). This in turn can potentially dilute findings about social support. For example, when recent studies involving an "important family member" found conflicting evidence for social support in tuberculosis medica- tion adherence, how are we to assess whether the intervention would have been differently affected if the important family member was a spouse versus a parent versus a sibling (Newell et al., 2006; Walley et al., 2001)? Within HIV support literature too, this type of aggregating occurs, as when friends and intimate partners are combined as "peers" (Derlega, Winstead, Oldfield, \& Barbee, 2003), or partners and blood relatives as "family" (Vandehey \& Shuff, 2001).

Spouses/partners are thought to play a particularly important role in providing social support. Generally thought to be the most important relationship (Revenson, 1994), and therefore a cornerstone of support provision, the evidence has produced decidedly mixed results (Ridder, Schreurs, \& Kuijer, 2005; Martire, Schulz, Keefe, Rudy, \& Starz, 2007). A meta analysis of literature involving family support during chronic illness found that interventions which involved only spouses did somewhat better than those that involved "mixed family" in the intervention (Martire, Lustig, Schulz, Miller, \& Helgeson, 2004), thereby highlighting the need to measure the sources of support independently. As for analyses looking specifically at non-partner sources of support, the data is either not disaggregated enough to answer specific questions about non-partner sources (Derlega et al., 2003; Vandehey \& Shuff, 2001) or the literature shows a range of results (Kimberly \& Serovich, 1996).

Previous research has argued that gay men tend to rely on their peer social networks more than heterosexuals (Nott et al., 1995). One reason given for this is that men may have strained relationships with family (Hays, Chauncey, \& Tobey, 1990; Kadushin, 1999; Kurdek \& Schmitt, 1987). However, others have noted that though the partner is extremely important in coping with HIV, that gay men, too, like heterosexual couples, often find support from the partner to be problematic and view friends' support at times more positively (Haas, 2002). There is not enough work yet in the field of support for HIV medication 
adherence among gay couples to know how distinct sources of social support-partners, peers and family - may have different influences on medication adherence.

Our goal for this paper is to explore the types of support for antiretroviral medication adherence reported by gay couples that they receive from sources in their social network other than their partners. We previously enumerated the daily support practices for adherence by partners among co-residing gay couples (Wrubel, Stumbo, \& Johnson, 2008, 2010). In that work we outlined the numerous and diverse ways in which HIV+ seroconcordant and serodiscordant couples offer support for HIV medication adherence. In this paper we explore both perceived and received support from family and friends, as distinct from the provision of support by partners.

\section{Method}

\section{Sample}

This study draws on data from the first phase of the Duo Project, a three-phase study of how relationship dynamics influence HIV medication adherence. In the first phase, from December 2006 to March 2007, 20 gay male couples were recruited for one in-depth interview about their relationship, their health care practices and HIV medication adherence issues.

Eligible participants were 18 or older, had been in a relationship and co-residing for a minimum of 3 months, and at least one of the men had to be HIV+ and on an acknowledged antiretroviral medication (ART) regimen for the past 30 days or more. Couples were recruited from local HIV care newsletters, referrals from other studies, HIV clinics and gay venues. Flyers were used to advertise the study, and interested persons were instructed to call the study telephone for more information and for screening. The telephone screening was used to confirm eligibility criteria, and eligible couples were scheduled for the interview.

\section{Procedures}

The two individuals in each couple were interviewed simultaneously but separately and were asked about their relationship, general health issues, HIV treatment, and medication adherence practices and support for adherence from the partner and others in the social network. Participants were asked to respond to questions generally but were also asked to provide a narrative of a specific recent event. The interview protocol was developed based on relationship and treatment adherence literatures. Questions included items about how many members of their network knew of their HIV status and medication regimens, what (if any) support they provided around mediation-taking, and whether they said or did things that were unhelpful in their medication taking.

Narrative data were audio recorded then transcribed for analysis. Transcribed interviews were entered into ATLAS.ti, a software program for the management and analysis of narrative data.

\section{Qualitative Analysis}

As a first step, we used a team-based approach to developing codes and coding the narratives (Fernald \& Duclos, 2005; MacQueen, McLellan, Kay, \& Milstein, 1998). The three team members began the analysis of the narrative data with broad questions: what are the couple dynamics around medication adherence practices? What kinds of support for HIV adherence are others in the social network offering? The team read the narrative accounts repeatedly with these questions in mind, articulated more specific questions based on these close readings, and developed codes that reflected what was said in the interviews. Codes were further refined into index codes to demarcate themes and marker codes to note the presence of actions, attitudes, feelings, and experiences that were relevant to the study questions (MacQueen et al., 1998; Seidel \& Kelle, 1995).

The qualitative team developed the coding protocol using interviews from five couples (i.e., 10 individual interviews) as no new codes emerged from the narratives and the codes were judged to be saturated (Bowen, 2008). The completed codebook included the codes, definitions of each code, and an exemplar of each code from a narrative. The remaining cases were coded by one team member and verified by the other two. Disagreements were resolved through discussion until $100 \%$ consensus was reached. For this analysis, we focused on the data which indicated support from non-partners. This data was coded into the commonly described categories of tangible, emotional and informational so as to be able to speak to current literature more directly.

\section{Results}

The sample included ten HIV + seroconcordant and ten serodiscordant couples. The mean age was 48.7 and the couples had been together an average of 9.8 years. See Table 1 for further demographic descriptive statistics.

Relational partners in our sample offered a wide range of all types of support for medication adherence (Wrubel et al., 2008). Men did not report receiving much tangible support from other social network members (see Table 2). Our goal is to describe support for adherence received from family and friends in the social network, including the importance of affective and informational support, and data from a group who believed that medication adherence was too personal to discuss outside the relationship.

\section{Affective Support}

We found a lack of specified tangible support sought or received from non-partner social network members. In contrast, the amount of affective support was highlighted as particularly useful and comforting to participants. For those who do not currently feel that they need tangible support for adherence, or who receive that support from their partner, men still report knowing that they can emotionally count on others as a valuable form of support. Almost half the sample indicated a perceived availability of affective support from friends and family, or an actual instance of emotional support for HIV medication adherence.

I: And do your friends do anything that helps or supports you around being HIV-positive?

$P$ : Nothing that I could pinpoint other than being, you know, I know that I have friends that I could rely on if I ever needed to talk or [...to] visit me in the hospital. (Ppt 019-1)

Men did not just seek or receive affective support from friends. For those with good relationships with their families, 
Table 1.

Sample Characteristics.

\begin{tabular}{|c|c|c|c|}
\hline \multicolumn{3}{|c|}{ Age—-mean years (SD) } & $48.7(9.0)$ \\
\hline \multicolumn{4}{|c|}{ Race/Ethnicity—n (\%) } \\
\hline \multicolumn{3}{|c|}{ Black } & $6(15.0)$ \\
\hline \multicolumn{3}{|l|}{ White } & $28(70.0)$ \\
\hline \multicolumn{3}{|l|}{ Latino } & $4(10.0)$ \\
\hline \multicolumn{3}{|l|}{ Other } & $2(5.0)$ \\
\hline \multicolumn{4}{|c|}{ Education—n (\%) } \\
\hline \multicolumn{3}{|c|}{$<$ HS graduate } & $3(7.5)$ \\
\hline \multicolumn{3}{|c|}{ HS graduate } & $8(20.0)$ \\
\hline \multicolumn{3}{|c|}{ Technical training or two years of college } & $13(32.5)$ \\
\hline \multicolumn{3}{|c|}{ College graduate } & $10(25.0)$ \\
\hline \multicolumn{3}{|c|}{ Advanced degree (MA/MS/PhD/JD/MD) } & $6(15.0)$ \\
\hline \multicolumn{4}{|c|}{ Annual Personal Income—n (\%) } \\
\hline \multicolumn{3}{|c|}{$<\$ 19,999$} & $24(60.0)$ \\
\hline \multicolumn{3}{|c|}{$\$ 20,000-\$ 39,999$} & $5(12.5)$ \\
\hline \multicolumn{3}{|c|}{$\$ 40,000$ - \$59,999 } & $5(12.5)$ \\
\hline \multicolumn{3}{|c|}{$\$ 60,000$ or more } & $6(15.0)$ \\
\hline \multicolumn{3}{|c|}{ HIV-positive } & $30(75.0)$ \\
\hline \multicolumn{3}{|c|}{ Months on Anti-Retroviral Medications_-mean (SD) } & $83.8(82.6)$ \\
\hline \multicolumn{3}{|c|}{ Antiretroviral Medication Adherence \%*—-mean (SD) } & $96.5(9.3)$ \\
\hline \multicolumn{3}{|c|}{ Couple relationship length in months_-mean (SD) } & $119.4(88.3)$ \\
\hline \multicolumn{3}{|c|}{ Couple length of time living together in months_-mean (SD) } & $106.1(88.0)$ \\
\hline \multicolumn{4}{|c|}{$\begin{array}{l}\text { Notes: } N=40 \text { for all variables except months on meds and adherence scores }(N= \\
\text { 30). *Adherence measured with a Visual Analog Scale from } 0-100 \mathrm{~cm} \text {; results } \\
\text { are then scored as a percent (Walsh et al., 2002). }\end{array}$} \\
\hline \multicolumn{4}{|c|}{$\begin{array}{l}\text { Table } 2 . \\
\text { Mentioned types of support by source. Sample } n=40 .\end{array}$} \\
\hline & Tangible & Informational & Affective \\
\hline Friends & 3 & 9 & 11 \\
\hline Family & 2 & 3 & 6 \\
\hline Total & 5 & 12 & 17 \\
\hline
\end{tabular}

we found that families could also be an important source of affective support.

I: Do these people [friends, family, etc.] do anything that helps or supports your partner around being HIV-positive?

P: Direct support? Not a whole lot. I mean he's my partner. $H e$ 's a member of the family. So I would say a lot of the support they would give him is in just treating him normally. You know he is a partner and a member of the family and, you know, they just treat him as anyone would be treated. And that's pretty much it. (Ppt 019-2)

\section{Informational Support}

If tangible support from friends and family was low, informational support, like affective support, was heavily endorsed and appreciated by participants. The most common source of informational support was friends. Most importantly, informational support from other HIV+ friends was common and encouraged:
P: Yeah. It's like when we have a certain rash or a certain thing that's happening, [...] then we look at it and say, "Oh that probably is because of that, or probably is because of this, why don't you take this? 'Cause my doctor gave me this because I have the same thing and, you know, ask your doctor'." And sometimes when I go to my doctor I say, "Hey, I need this, because my friend has something similar and --” [...] Because we are in the same boat. [...] With a guy or person who is negative, we cannot talk about, you know, nightmares, we cannot talk about sweats, we cannot talk about meds or doctors, 'cause they don't know. (Ppt 020-2)

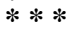

$P$ : [L]ike I said, it's like the HIV club. You know it's like they're a member too. [...] [E]very once in a while [...] we'll discuss side-effects, and what meds you're on, and "Oh, I was on that one and I couldn't deal with that one, honey. That one made me so ill." You know? And we'll, we'll girl talk about what this one did, and what that one did, and where you ever on this one. [...] It's like pill talk. [...] It's kind of a comradery of drugs, you know, what works for you, what doesn't work for you, are you on the same thing I'm on [...]. Because a lot of guys, especially in the chorus, we're on very close to the same cocktail, you know, because our numbers are pretty close to the same. (Ppt 046-2)

This type of informational support may be particularly important in HIV serodiscordant couples, where the HIV-negative partner may have less direct personal experience with HIV medications. The description below is from an HIV-negative participant regarding his partner's sources of support:

$P$ : Well I know C. does have a couple good friends who he keeps in contact with who are, you know, a very good source of information in terms of, you know, what's going on in terms of like research or like if a new drug comes out, you know, they're very on top of-you know one of his good friends who's down in L.A. is always sending out e-mails in terms of what's going on with HIV and AIDS in terms of like whether it be legislation or whether it be like drugs in the pipeline or that sort of thing. (Ppt 029-2)

Though friends, particularly other HIV+ friends, provided the bulk of informational support, family could also be a source of support. No one in the sample reported a fellow HIV+ family member, and thereby no family member had the intimate knowledge of HIV-related issues as HIV+ friends did. This did not, however, necessarily preclude informational assistance from family. Both members of one couple reported that one of their sisters consistently provided informational support in the form of internet information:

$P$ : They [family, friends, etc.] are very supportive. Like my sister-in-law, she, whenever some new drug [comes out], she looks it up on the internet just to see what kind of side effects and whatnot it is. (Ppt 023-1)

And his partner says:

P: 'You know, so I told her [about my new meds] and then she goes right straight to the Internet [...] and looked up everything and the side effects. So she knew the side effects before I even knew, before I got the printout from the pharmacy what possible side effects are. (Ppt 023-2)

"We don't really get into that"

For five men, the thought of asking for or receiving support for HIV medication adherence outside the partnership seemed 
almost unthinkable. The topic of being HIV+ or of taking medications was seen as too sensitive to involve others, be they family or friends. For these men, discussions of side effects, medication changes, or other adherence issues happened only with the partner, not other social network members.

This was particularly true for HIV-negative men in our sample, perhaps feeling protective of their partners:

I: Who among these people [friends, family etc.] know that your partner is HIV positive?

$$
P \text { : It's none of their business. (Ppt 05-1) }
$$

$* * *$

$P$ : I guess it's more of a privacy thing, [...]. So you have to be good friends, I guess, to really talk about that kind of stuff, that's pretty personal. And I, and I guess people that are on the meds take it just as personally as somebody that was doing cancer treatments, you know, whether or not they want to talk with somebody about their chemo or the pills they're taking, or something. 'Cause it's not really something you want to dwell on all the time with everybody'. (Ppt 044-2)

\section{Discussion}

Gay men in couples draw on many sources for support. However, they access different sources for different types of support. Our work extends earlier findings on the relevance of friends as an important source of support for gay men (Haas, 2002; Hays, Catania, McKusick, \& Coates, 1990). Among gay men coping with HIV and managing HIV medication adherence, studies have sometimes shown an equal reliance on "peers" — partners and friends (Hays, Catania et al., 1990; Hays, Chauncey et al., 1990). Our work provides less support for concluding that partners/spouses were more likely to provide emotional support, and that partners and friends provided tangible support equally (Dakof \& Taylor, 1990). Partners are the primary source of tangible support in the lives of those who have them (Haas, 2002; Revenson, 1994).

This study is based on a relatively small sample; the study was designed to elicit narratives of support from partners and other sources. The sample had overall high adherence, and therefore lacked variation in need for support. Poor adherers may access support in their social network differently than $\mathrm{HIV}+$ individuals with relatively good adherence, or may lack a substantive network altogether.

The current findings support the importance of primary relationships in the role of social support and treatment adherence. There is a rich literature establishing the role of primary partners in the adoption and maintenance of health promoting or health compromising behaviors. Findings suggest that when there is a primary partner, opportunities for adherence related support from other people may be restricted or not sought. From a relationship theory perspective, the findings have implications for further exploring the role of different types of relationships on health-related social support.

Future quantitative survey work could explore the provision of support for medication adherence more systematically from all social network members. As tangible support was recently reported to be the most important element in adherence, it is particularly important to note the sources of that form of support (Rueda et al., 2006). Future intervention development would be served by focusing on detailed assessments of the sources of social support. For HIV+ individuals who have partners or spouses, interventions focusing on tangible assistance in addition to emotional support may be warranted. For $\mathrm{HIV}+$ individuals without a primary partner, interventions could focus on enhancing affective and informational support from friends and family, or encourage the development of tangible assistance seeking from family and friends. Future interventions based on better understandings of the sources of support needed by couples who are HIV+ concordant or serodiscordant could help with adherence support and better clinical outcomes.

\section{References}

Ammassari, A., Trotta, M. P., Murri, R., Castelli, F., Narciso, P., Noto, P., et al. (2002). Correlates and predictors of adherence to highly active antiretroviral therapy: Overview of published literature. Journal of Acquired Immune Deficiency Syndromes, 31, S123-127. doi:10.1097/00126334-200212153-00007

Berkman, L. F., \& Syme, S. L. (1979). Social networks, host resistance, and mortality: A nine-year follow-up study of Alameda County residents. American Journal of Epidemiology, 109, 186-204.

Bowen, G. A. (2008). Naturalistic inquiry and the saturation concept: A research note. Qualitative Research, 8, 137-152. doi:10.1177/1468794107085301

Catz, S. L., Kelly, J. A., Bogart, L. M., Benotsch, E. G., \& McAuliffe, T. L. (2000). Patterns, correlates, and barriers to medication adherence among persons prescribed new treatments for HIV disease. Health Psychol, 19, 124-133. doi:10.1037/0278-6133.19.2.124

Dakof, G. A., \& Taylor, S. E. (1990). Victims’ perceptions of social support: What is helpful from whom? Journal of Personality and Social Psychology, 58, 80-89. doi:10.1037/0022-3514.58.1.80

Derlega, V. J., Winstead, B. A., Oldfield, I. E., \& Barbee, A. P. (2003). Close relationships and social support in coping with HIV: A test of sensitive interaction systems theory. AIDS Behav, 7, 119-129. doi:10.1023/A:1023990107075

DiMatteo, M. R. (2004). Social support and patient adherence to medical treatment: A meta-analysis. Health Psychology, 23, 207-218. doi:10.1037/0278-6133.23.2.207

Fernald, D. H., \& Duclos, C. W. (2005). Enhance your team-based qualitative research. Annals of Family Medicine, 3, 360-364. doi:10.1370/afm.290

Haas, S. M. (2002). Social support as relationship maintenance in gay male couples coping with HIV or AIDS. Journal of Social \& Personal Relationships, 19, 87-111. doi:10.1177/0265407502191005

Hamilton, M. M., Razzano, L. A., \& Martin, N. B. (2007). The relationship between type and quality of social support and HIV medication adherence. Journal of HIV/AIDS \& Social Services, 6, 39-63. doi:10.1300/J187v06n01_04

Hays, R. B., Catania, J. A., McKusick, L., \& Coates, T. J. (1990). Help-seeking for AIDS-related concerns: A comparison of gay men with various HIV diagnoses. American Journal of Community Psychology, 18, 743-755. doi:10.1007/BF00931240

Hays, R. B., Chauncey, S., \& Tobey, L. A. (1990). The social support networks of gay men with AIDS. Journal of Community Psychology. Special Issue: AIDS and the community, 18, 374-385.

Kadushin, G. (1999). Barriers to social support and support received from their families of origin among gay men with HIV/AIDS. Health \& Social Work, 24, 198-209.

Kimberly, J. A., \& Serovich, J. M. (1996). Perceived social support among people living with HIV/AIDS. American Journal of Family Therapy, 24, 41-53. doi:10.1080/01926189508251015

Kulik, J. A., \& Mahler, H. I. (1989). Social support and recovery from surgery. Health Psychol, 8, 221-238. doi:10.1037/0278-6133.8.2.221

Kurdek, L. A., \& Schmitt, J. P. (1987). Perceived emotional support from family and friends in members of homosexual, married, and 
heterosexual cohabiting couples. Journal of Homosex, 14, 57-68. doi:10.1300/J082v14n03_04

Lewis, M. A., \& Rook, K. S. (1999). Social control in personal relationships: Impact on health behaviors and psychological distress. Health Psychology, 18, 63-71. doi:10.1037/0278-6133.18.1.63

MacQueen, K. M., McLellan, E., Kay, K., \& Milstein, B. (1998). Codebook development for team-based qualitative analysis. Cultural Anthropology Methods, 10, 31-36.

Martire, L. M., Lustig, A. P., Schulz, R., Miller, G. E., \& Helgeson, V. S. (2004). Is it beneficial to involve a family member? A metaanalysis of psychosocial interventions for chronic illness. Health Psychol, 23, 599-611. doi:10.1037/0278-6133.23.6.599

Martire, L. M., Schulz, R., Keefe, F. J., Rudy, T. E., \& Starz, T. W. (2007). Couple-oriented education and support intervention: Effects on individuals with osteoarthritis and their spouses. Rehabilitation Psychology, 52, 121-132. doi:10.1037/0090-5550.52.2.121

Murphy, D. A., Marelich, W. D., Hoffman, D., \& Steers, W. N. (2004). Predictors of antiretroviral adherence. AIDS Care, 16, 471-484. doi:10.1080/09540120410001683402

Newell, J. N., Baral, S. C., Pande, S. B., Bam, D. S., \& Malla, P. (2006) Family-member DOTS and community DOTS for tuberculosis control in Nepal: Cluster-randomised controlled trial. Lancet, 367, 903-909. doi:10.1016/S0140-6736(06)68380-3

Nott, K. H., Vedhara, K., \& Power, M. J. (1995). The role of social support in HIV infection. Psychological Medicine, 25, 971-983. doi:10.1017/S0033291700037466

Power, R., Koopman, C., Volk, J., Israelski, D. M., Stone, L., Chesney, M. A., et al. (2003). Social support, substance use, and denial in relationship to antiretroviral treatment adherence among HIV-infected persons. AIDS Patient Care and STDS, 17, 245-252. doi:10.1089/108729103321655890

Primomo, J., Yates, B. C., \& Woods, N. F. (1990). Social support for women during chronic illness: The relationship among sources and types to adjustment. Research in Nursing \& Health, 13, 153-161. doi:10.1002/nur.4770130304

Revenson, T. A. (1994). Social support and marital coping with chronic illness. Annals of Behavioral Medicine, 16, 122-130.

Revenson, T. A., Schiaffino, K. M., Majerovitz, S. D., \& Gibofsky, A.
(1991). Social support as a double-edged sword: The relation of positive and problematic support to depression among rheumatoid arthritis patients. Social Science \& Medicine, 33, 807-813. doi:10.1016/0277-9536(91)90385-P

Ridder de, D. T. D., Schreurs, K. M. G., \& Kuijer, R. G. (2005). Is spousal support always helpful to patients with asthma or diabetes? A prospective study. Psychology \& Health, 20, 497-508. doi:10.1080/14768320500098699

Rueda, S., Park-Wyllie, L. Y., Bayoumi, A. M., Tynan, A. M., Antoniou, T. A., Rourke, S. B., et al. (2006). Patient support and education for promoting adherence to highly active antiretroviral therapy for HIV/AIDS. Cochrane Database System Review, 3, CD001442.

Seidel, J., \& Kelle, U. (1995). Different functions of coding in the analysis of textual data. In U. Kelle (Ed.), Computer-dided qualitative data analysis: Theory, methods, and practice. Thousand Oaks, CA: Sage.

Vandehey, M. A., \& Shuff, I. M. (2001). HIV infection and stage of illness: A comparison of family, friend, and professional social-support providers over a 2-year period. Journal of Applied Social Psychology, 31, 2217-2229. doi:10.1111/j.1559-1816.2001.tb00172.x

Walley, J. D., Khan, M. A., Newell, J. N., \& Khan, M. H. (2001). Effectiveness of the direct observation component of DOTS for tuberculosis: A randomised controlled trial in Pakistan. Lancet, 357, 664-669. doi:10.1016/S0140-6736(00)04129-5

Walsh, J. C., Mandalia, S., \& Gazzard, B. G. (2002). Responses to a 1 month self-report on adherence to antiretroviral therapy are consistent with electronic data and virological treatment outcome. AIDS, 16, 269-277. doi:10.1097/00002030-200201250-00017

Wrubel, J., Stumbo, S., \& Johnson, M. O. (2008). Antiretroviral medication support practices among partners of men who have sex with men: A qualitative study. AIDS Patient Care \& STDS, 22, 851-858. doi:10.1089/apc.2008.0037

Wrubel, J., Stumbo, S., \& Johnson, M. O. (2010). Male same sex couple dynamics and support for HIV medication adherence: The question of received social support. Journal of Personal and Social Relationships, 27, 553-572. doi:10.1177/0265407510364870 